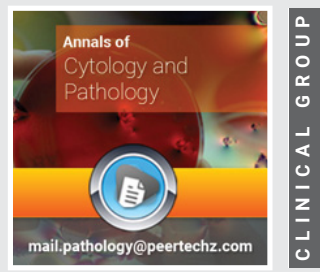

\title{
Immunohystochemical profile
} of cytokeratins $(5,7,14,18$,

\section{0 ) in retrospective cases of breast fibroadenomas}

Received: 22 February, 2020

Accepted: 19 March, 2020

Published: 20 March, 2020

*Corresponding author: Andreia Fabiana do Vale Franco, Postgraduate Student of Department of Anatomic Pathology, Federal University of Sao Paulo (UNIFESP/ EPM) - Sao Paulo, Brazil, E-mail: afvfranco@gmail.com Keywords: Fibroadenoma; Cytokeratin; Immunohistochemistry

https://www. peertechz.com

\section{Check for updates}

\author{
Marcia Bernardo ${ }^{*}$, Andreia Fabiana do Vale Franco ${ }^{2 *}$, Gil \\ Facina $^{3}$ and Angela Flavia Logullo Waitzberg ${ }^{2}$ \\ ${ }^{1}$ Perola Byington Hospital - Sao Paulo/Brazil \\ 2Department of Anatomic Pathology, Federal University of Sao Paulo (UNIFESP/EPM) - Sao Paulo/ \\ Brazil \\ ${ }^{3}$ Department of Gynecology, Federal University of Sao Paulo (UNIFESP/EPM) - Sao Paulo/Brazil \\ *The authors equally contributed for this article
}

\begin{abstract}
Introduction: Fibroadenomas (FAs) are the most common benign tumors in the breast. Described as a biphasic stromal and epithelial lesion, it is usually stable and clinically well managed. Although the cytokeratins (CKs) distribution among ductal cells is well described in carcinomas and normal breast tissue, in FAs the differentiation and distribution of epithelium CK profile is scarcely known.

Objectives: To analyze the immunoexpression of the cytokeratin profile $(5,7,14,18$ and 20$)$; to evaluate whether the CK5 $5^{+}$and $C K 14^{+}$cells (progenitor cell markers) population is preserved and comparable to normal breast tissue.
\end{abstract}

Materials and methods: A retrospective observational linear study of FAs diagnosed and surgically treated at Perola Byington Hospital, São Paulo, Brazil (January and March/2006) was evaluated. Paraffin embedded tumor samples of 104 cases were included in a tissue microarray. CKs expression was assessed by counting the positive and negative number of ductal cells contained in terminal ductal acinar units and also registering the basal or luminal position of positive cells. Ki67 expression score evaluated the contingent of positive cells in 100 epithelial cells.

Results: FA epithelial component showed positive expression to CK5, 7, 14 and 18, and negative expression to CK20. Stromal cells were always negative for see these markers. The percentage and distribution of positive cells were comparable to the normal breast profile. Progenitor cells contingent was equal or higher than in normal breast tissue. Proliferation score in FAs was maintained comparable to the normal tissue, and correlated to CK5 expression ( $p=0.0368$ ). However, this score was not associated with expression of CK14, CK18 or tumor size. CK18 expression was statistically significant when compared to the early age ( $p=0.0368$ ). In this study, 14 cases relapsed, but this outcome was not associated to clinical variables, Ki67 score or any CKs expression. CK5 expression in basal cells did not present statistical differences in relation to CK18 $(p=0.3438)$ and CK14 ( $p=0.3105)$ expression. CK14 and CK18 expression were mutually exclusive $(p=0.0022)$.

Conclusions: We concluded that, although inserted in a distinct environment and prone to an epithelial mesenchymal influence, the ductal epithelium of FAs exhibited a CKs profile and proliferation similar to the progenitor cells profile in normal breast tissue, suggesting a preserved differentiation process.

\section{Introduction}

The human mammary gland epithelia were generally classified, until recently, as a tissue containing two morphologically distinct cell populations: luminal and basal glandular myoepithelial cells. Currently, there is a more detailed description of progenitor cells expressing highweight cytokeratins, which are considered basal cells. These elements can differentiate into glandular and myoepithelial cells by means of other transient elements, intermediate cells located in the basal and suprabasal layers, as in the luminal compartment [1]. 
Werner, et al. [1] demonstrated the richness and heterogeneity of the ductal cell population. Subsequent descriptions of more or less differentiated cell distribution patterns with luminal and basal patterns have been reported in various breast diseases, such as papillary lesions, hyperplasia, in situ carcinoma and lobular carcinomas [2-4]. To identify these cells or their different stages of maturation, distinct keratin expression may be used. Cytokeratins are keratin proteins that make up intermediate filaments found in the intracytoplasmic cytoskeleton of epithelial tissue, arranged and expressed in organ specific [5,6]. In epithelial cells they function is important to the cellular structuring and maintenance of the cellular shape, besides influencing the maintenance of polarity, migration and healing. When cells lose adhesion and gain motility CK expression are transient and definitive changes in their systems that interfere with polarity and cell adhesion occur [7]. Alterations of cytokeratin profile may be a subtle and early modification of epithelial cells in metaplasia, dysplasia and neoplasia [3].

However, in addition to the epithelial population, the mammary gland contains an important contingent of stromal cells, which indirectly influence the epithelial population. One of the indirect effects of stromal cells is to control the proliferation and differentiation of the epithelial component [8].

In this context of the interrelationship of ductal and stromal cells, FAs are fibroepithelial lesions where there is a progressive increase of both mammary components, stromal and epithelial and the mesenchymal cells arise proportionally with a potential paracrine effect on the oppressed epithelial cells. They are formed by the proliferation of specialized stroma with secondary distortion of the preexisting glands, which contains a single layer of cuboidal cells and myoepithelial cells [9]. The stroma is usually myxoid and compresses the epithelial cells in a concentric arrangement progressively. Clinically FA comprehends the most common benign tumors in breast, especially in younger women, are usually stable and clinically well managed. FAs may be single or multiple, and the same patient may have one or more lesions throughout life $[9,10]$. They are devoid of atypical and mitosis, and are called cellular FA when their diagnosis is more cellular [11].

The malignant transformation of FA, albeit an extremely rare event, is associated with the Phyllodes tumor (PT). Literature data suggest that this entity would be the malignant variant of FA $[12,13]$.

Although these two entities are biphasic, that is, they contain epithelial and stromal components, molecular studies comparing the two types of tumors are rare $[14,15]$. Noguchi and colleagues recorded the first study on clonality of these entities by amplification and PCR, showing that FAs are polyclonal in both stroma and epithelium, while PT is polyclonal in the epithelium, but monoclonal in the stroma [16]. More recently specific mutations in MED-12 gene, similar to those found in uterine leyomiomas, were largely reported in FAs and up to $60 \%$ of cases [17]; and also in Phyllodes tumors, albeit more frequently in benign and border line lesions. [15,17].
The evidence of common genetic mutational alterations in both lesions has risen the idea of a possible continuum and association, which was evidenciated by pareja, et al. in PT lesions bearing fibroadenoma-like areas harboring the same mutations of those of classic PT microdissected areas [18].

Although the CKs distribution among ductal cells is well described in carcinomas and normal breast tissue, in FAs the differentiation and distribution of epithelium is scarcely known. In the literature there are several studies reporting changes in epithelial population profile according to the different expression of cytokeratin in subpopulations in various breast diseases; however, such evaluation of ductal epithelium in FA is scarce. Previous studies in fibroadenomas reporter epithelial profile with similar proliferation index that normal breast tissue.

The distribution of different ductal cell subtypes at different stages and maturation could imply on a potential switch favoring were subset in detriment of others or even influence on differentiation or proliferation process. Since epithelial cells are prone to mesenchymal cells influence, early and subtle phenotypic alterations would be reflected in cytokeratin structure and profile and could rise a alert of FA lesions with potential risk of clonality.

\section{Objectives}

$\checkmark$ To describe the frequency and profile of different cellular subpopulations in the glandular epithelium in FAs, according to $7,14,18$ and 20 cytokeratin immunoexpression;

$\checkmark$ To observe the frequency of progenitor's cells status in these lesions through the immunoexpression of cytokeratins 5 and 14; in order to verify a shift of maturation process;

\section{To evaluate proliferation through Ki67 expression.}

\section{Material and methods}

The study was performed in a consecutive series of 104 patients who were evaluated surgically treated and diagnosed at the Perola Byington Hospital, and who underwent a nodulectomy from January to March 2006. Only patients diagnosed with FA without preview entities, and cases with paraffin blocks and Hematoxylin-Eosin (HE) stained slides available and reviewed by the pathologist were included. Patients diagnosed with FA associated with others pathologies or inappropriate samples (without slides or paraffin blocks) were excluded. Clinical data regarding variables such as age, laterality, size tumor and recurrence were collected and organized from the clinical files.

Representative areas containing both components of the benign fibroepithelial lesions were marked for Tissue Microarray (TMA). And arranged in two distinct TMAs from the 104 cases elected for the study, as previously described in the literature $[19,20]$. Briefly, from the original cut stained by $\mathrm{HE}$, the areas of interest were marked with a sharpie pen; then the equivalent area in the original paraffin block was marked. 
From this point, the selected areas were transferred to the receiving block through the use of Tissue Microarrayer TMA Master (3D HISTECH). The TMA block was made with $1.5 \mathrm{~mm}$ cylinders, with samples arranged in 13 rows and 8 columns [20]. From this block, 20 serial histological sections were prepared on silanized slides by a $4 \mu \mathrm{m}$ mechanical microtome previously treated with special adhesive film (Instrumedics Inc. Hackensack, NJ USA). All reactions were accompanied by a positive control, known to be positive for each antibody tested, and a negative control of the reaction (removal of the primary antibody and removal of the secondary complex).

\section{Immunohistochemistry}

The slides were then submitted to the immunohistochemical technique for each marker. The technique followed the traditional and routine steps to the laboratory of Hospital A.C. Camargo Cancer Center. All reactions were accompanied by a positive control, known to be positive for each antibody tested, and a negative control of the reaction (removal of the primary antibody and removal of the secondary complex).

Slides containing the histological sections were deparaffinized with xilol (3 times, 5 minutes each) and rehydrated with alcohol and water. The antigenic retrieval was realized with citrate buffer $\mathrm{pH} 6.0$ and/or ethylenediamine tetraacetic acid (EDTA) + trisaminomethane (TRIS) pH 9.0 and/or EDTA pH 8.0, and heated in a pressure cooker for 15 or 40 minutes according of the variable need for each antibody.

After antigenic retrieval, the histological slides were cooled at room temperature (15 minutes) and washed with running water ( 5 minutes) [21]. The slides were placed in 3\% hydrogen peroxide ( 3 times, 5 minutes each) for blocking the endogenous peroxidase and then washed in running water ( 5 minutes). The cuts were subjected to blocking of non-specific proteins with casein (Protein Block Serum-Free-DakoCytomation, Carpinteria, USA) at room temperature (20 minutes).

The primary antibody was incubated in the sections at room temperature ( 2 hours); the dilution of the antibodies followed the recommendations of each manufacturer after the adaptation to the laboratory of the Hospital A.C. Camargo Cancer Center (Table 1). Then, for signal detection slides were washed with saline-phosphate buffer (PBS) ( 3 times, 5 minutes each). After this, they were incubated with a polymer (horse radish peroxidase).

Staining was performed using 3,3 diaminobenzidine tetrachloride (Dako Cytomation, Carpinteria, USA). The specimens were counterstained with Harris hematoxylin, dehydrated with alcohol and xylol and mounted with coverslip. The 20 sections ( $4 \mu \mathrm{m}$ thick slices) of TMA blocks were obtained on silanized slides, where the markers were investigated (table 1) (attached protocol - 2).

The evaluation of each immunohistochemical reaction on the samples contained in the epithelial and stromal TMAs underwent double evaluation. In the stroma TMA, a possible positivity for the markers evaluated in the stromal cells was
Table 1: Markers used in immunohistochemistry.

\begin{tabular}{|c|c|c|c|c|}
\hline Antibody & Clone & Manufacturer & Dilution & Retrivel antigenic \\
\hline CK5 & Clone XM26 NCL-CK5 & Novocastra & $1 / 3000$ & Citrate Buffer \\
\hline CK7 & Mono OV-TL & Dako & $1 / 2000$ & Citrate Buffer \\
\hline CK14 & NCL-LL002 & Novocastra & $1 / 1500$ & Citrate Buffer \\
\hline CK18 & DC 10 & Novocastra & $1 / 50$ & Citrate Buffer \\
\hline CK20 & Mono KS 20.8 & Biocare Medical & $1 / 1000$ & Citrate Buffer \\
\hline
\end{tabular}

analyzed, and the presence of positivity in the ductal cells was evaluated in the TMA of the epithelium. Sometimes the information was corroborated with epithelial component present in the stromal samples.

In the epithelial component, for each cytokeratin expression, the results were described in two different ways: first - according to the type of cell that was stained, considering myoepithelial, basal and luminal, and second - also considering a general percentage of the number of positive cells in relation to the whole contained in that sample. The putative positive cells in the stromal components were repeated as a percentage of 10ocells evaluated

The myoepithelial cells were considered as the elongated elements dysplayed over the basal membrane (BM) around the ductal structure, the basal cells were considered the ductal cells closest to the $\mathrm{BM}$, and the luminal ones were in the apical position in contact with the ductal lumen. Thus, both the position and the distribution of positive cells were contemplated in the evaluation.

In the evaluation of the Ki67 expression in ductal cells were evaluated the complete ductal structures arranged in the samples and counted the total cells present. The positive cells were analyzed in five consecutive large power fields, and the positivity ratio for Ki67 demonstrated proliferation in each sample [16].

To analyze the statistical significance of the patient's age, size tumor, and proliferative index on tumoral recurrence parametric statistical tests with normal distribution (test t-student) were used and nonparametric tests (Fisher's exact test) in the case of normality has not been identified. In order to test the mean differences in the cytokeratin's expression in the epithelium was used the McNemar test. The level of statistical significance considered was $5 \%$.

\section{Results}

\section{Demographic, clinical and epidemiological data}

The epidemiological data collected in the patient's medical records reveal that this series is comparable to others in the literature, reflecting the normal distribution of patients who present FAs as the main complaint without association with other comorbidities and the recurrence pattern average value. Table 2 shows the epidemiological variables distribution.

Our series presented a mean age of 27 years (median of 25 years). As expected, the distribution shows a predominance of 
Table 2: Epidemiological variables of the evaluated patients with fibroadenoma. Epidemiological Variables

$$
\text { Number of cases }
$$

Percentage

\begin{tabular}{|c|c|c|}
\hline Age & & \\
\hline$<20$ years & 22 & $21.2 \%$ \\
\hline Between 20 and 40 years & 70 & $67.3 \%$ \\
\hline$>40$ years & 12 & $11.5 \%$ \\
\hline Total & 104 & $100 \%$ \\
\hline \multicolumn{3}{|l|}{ Size of tumor } \\
\hline$<2.0 \mathrm{~cm}$ & 13 & $12.5 \%$ \\
\hline Between 2.0 and $4.0 \mathrm{~cm}$ & 71 & $68.3 \%$ \\
\hline$>4.0 \mathrm{~cm}$ & 20 & $19.2 \%$ \\
\hline Total & 104 & $100 \%$ \\
\hline \multicolumn{3}{|l|}{ Laterality } \\
\hline Right & 49 & $47.1 \%$ \\
\hline Left & 55 & $52.9 \%$ \\
\hline Total & 104 & $100 \%$ \\
\hline \multicolumn{3}{|l|}{ Recurrence } \\
\hline Yes & 14 & $13.5 \%$ \\
\hline No & 90 & $86.5 \%$ \\
\hline Total & 104 & $100 \%$ \\
\hline
\end{tabular}

young patients, between 20 and 40 years. The size of the lesions excised ranged from $1.2 \mathrm{~cm}$ (minimum) to $8.2 \mathrm{~cm}$ (maximum), being expression of the majority of tumors between 2 and $4 \mathrm{~cm}$. With regard to laterality $47.1 \%(n=49)$ were in the right breast and $52.9 \%(n=55)$ in left breast. Among the studied cases, $13.5 \%(n=14)$ presented recurrence on the follow up period.

\section{Cytokeratins immunoexpression frequencies in fibroa- denomas (FAs)}

a) Cytokeratin 5 (CK5): Previous studies report that CK5 expression is positive in basal cells [3]. In our study, as expected the stroma of the FA cases did not present any reactivity to CK5. However, the epithelial component represented as the ductal cells presented variable positivity between the cell types. The basal cells presented $39 \%(n=40)$ of positivity for $\mathrm{CK}_{5}$, and in the luminal cells this positivity was $24 \%(n=24)$. When analyzed basal and luminal cells together, the positivity represented $37 \%(n=38)$ of epithelial cells. Of the total cases studied, only $2 \%(n=2)$ did not present any reactivity for $\mathrm{CK}_{5}$ in any the epithelial component sample myoepithelial cells (Figure 1A).

b) Cytokeratin 7 (CK7): In our samples, all epithelial cells showed strong diffuse positivity for CK7 (100\%, $\mathrm{n}=104)$. However, myoepithelial and stromal cells did not present expression for this $\mathrm{CK}$ in all cases evaluated (Figure 1B).

c) Cytokeratin 14 (CK14): The evaluation of epithelial component demonstrated positive expression for CK14, mainly in myoepithelial and basal ductal cells.
Of all cases evaluated, $61.54 \%$ (64 cases) had positive immunoexpression, and $38.5 \%(n=40)$ did not present any immunostaining for this marker. Similarly to other CKs, expression of CK14 in stromal cells was not observed in all samples.

Among the FA cases with CK14 staining distribution of positive cells was predominantly in basal cells but a minority of cases showed luminal apical cells with some staining. Immunoexpression found in myoepithelial cells in $27.9 \%$ of cases $(n=29)$, and in basal and myoepithelial cells it was present in $29.8 \%$ of the cases $(n=31)$. Exclusive reactivity in basal cells was observed only in $1.92 \%$ of the cases $(n=2)$, and luminal cells showed immunoexpression of this marker in $25 \%$ of the assessed cases $(n=26)$ (Figure 1C e 1D).

d) Cytokeratin 18 (CK18): CK18 is considered a marker of luminal cells $[23,24]$ and immunoexpression was largely present in $86.5 \%(n=90)$ of cases. However, some basal cells, $11.5 \%(\mathrm{n}=12)$, also showed positivity immunoexpression for this CK. Myoepithelial and stromal cells did not express CK18 in all cases $(1.9 \%$, $\mathrm{n}=2$ ) (Figure $1 \mathrm{E}$ and $1 \mathrm{~F}$ ).

e) Cytokeratin 20 (CK20): CK20 is not considered a marker of mammary epithelial cells [23] and, as expected, did not observed immunoexpression in all the cases studied.

f) Ki67 antigen: Ki67 is a nuclear antigen expressed in cells during the proliferation process. In breast carcinomas it is used as prognostic tool, since is considered a luminal $\mathrm{B}$ feature when the level of immunoexpression exceeds $14 \%$ [22]. Its elevated expression was related to increased mitotic activity, cellular indifferentiation and invasion tendency. Only 1 case did not present positive expression to Ki67 in all samples obtained.

Considering the limited area of TMA samples, the immunohistochemical evaluation of Ki67 was performed by analyzing the number of positive cells in five consecutive large powers. This analysis showed less than eight positive cells in $51 \%$ of cases $(n=53) ; 37 \%(n=38)$ presented between eight and twenty positive cells; $11 \%(n=12)$ showed more than twenty positive cells; only 1 case had no reactivity to Ki67.

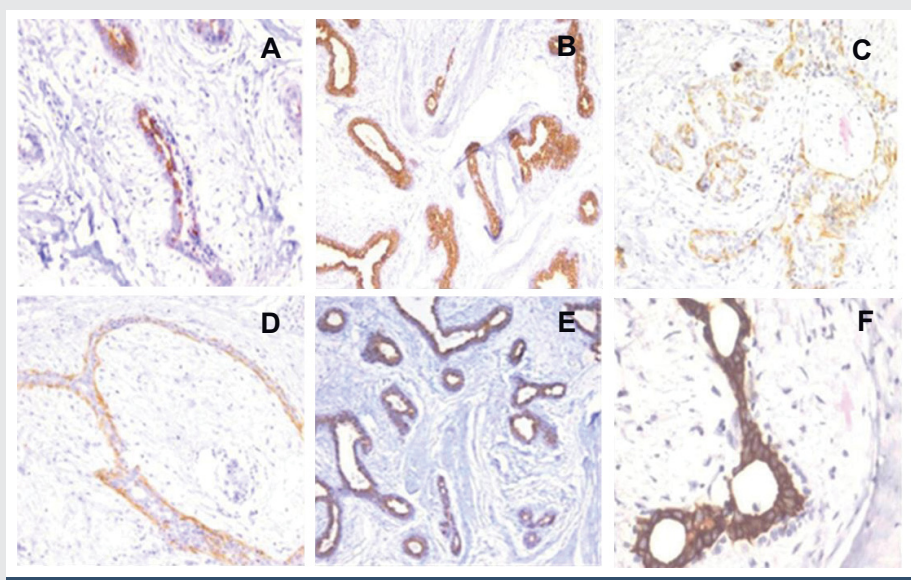

Figure 1: Photomicrograph of CKs immunoexpression in FAs. 


\section{Statistical analysis of clinical variables and proliferation}

Age, laterality and tumor size of the patients when we compare the frequency of they did not show significant differences statistically. Larger tumors did not show significant cell proliferation index when compared to smaller tumors. Thus, tumor size cannot be used as a determinant variable for proliferation index in FA.

When evaluate the presence or absence of tumor recurrence with age, a significant trend was observed $(p=0.06)$ between the cases in which there was a response and those that did not have a tumor response.

\section{Relationship between Ki-67 and cytokeratins evaluated (CK5, CK14 and CK18)}

Regarding of expression, the observed data were further classified into 3 categories of positivity to analyze possible correlation between CK and Ki67 expression (CK5: 0 to 5\%, 6 to $25 \%$, and >25\%; CK14: 0 to $5 \%, 6$ to $10 \%$, and 11 to $30 \%$; CK18: 0 to $80 \%, 81$ to $90 \%$ and 91 to $100 \%$ ).

Statistical significance was observed when comparing Ki67 results with the CK5 group expressing more than $25 \%$ of cells compared to the other groups expressing less than $25 \%$ cells (p<0.05) (Graphic 1).

The results of CK14 and CK18 expression categories showed no statistical difference in relation to cell proliferation index.

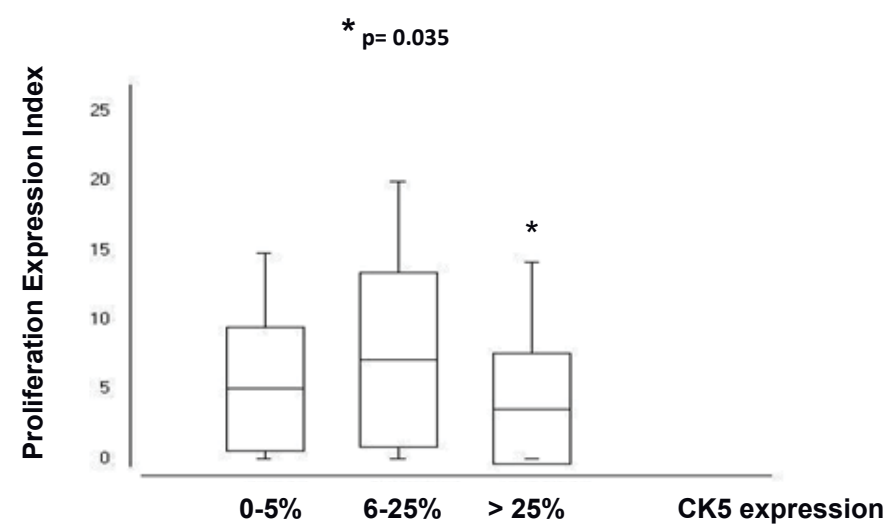

Graphic 1: Comparison between Ki67 results with CK5 group $(p<0.05)$.

\section{Relationship between cytokeratin immunoexpression and clinical variables}

The mean CK expression studied in cases was not statistically significant show recurrence, being $\mathrm{CK}_{5}$ expression $p=0.27$; CK14 $p=0.76$; and CK18 $p=0.76$.

To compare the expression of CKs in relation to the other clinical variables (age, laterality, tumor size) we used the same category of CK positivity index previously described.

Analysis of tumor size was not significant when compared to $\mathrm{CK} 5, \mathrm{CK} 14$ and CK18 (respectively $p=0.59 ; p=0.38$; and $p=0.60$ ). When comparing the expression of CK5 and CK14 with age, no significance was observed. However, when age was compared with CK18 expression, a significant value was observed $(p=0.04)$. A multiple comparison analysis indicated that younger patients (mean $24.9 \pm 11.4$ ) had CK18 expression rates below $80 \%$.

\section{Relationship between immunohistochemistry expres- sion of different CKs}

In general luminal and basal CKs are co-expressed. Analyzing the difference in the expression of CKs in the tumor epithelium, it was possible to observe that there was no disagreement between $\mathrm{CK}_{5}$ and $\mathrm{CK} 18$, that is, these CKs present co-expression of $\mathrm{CK}_{5}$ in the basal cells and CK18 in the luminal layer ( $p=0.34)$. Regarding CK5 and CK14 in the tumor epithelium also showed disagreement ( $\mathrm{CK}_{5}$ and $\mathrm{CK}_{14}$ in the basal cells $p=0.31$ ). The last but not least analysis was between CK14 and CK18 in the tumor epithelium where it was observed that there is disagreement between these CKs $(p=0.002)$ indicating that the expression of CK14 and CK18 mutually exclusive.

\section{Discussion}

\section{About the sample}

Studying a chronologically ordered sequence of 104 surgically treated FA cases at Perola Byington Hospital we were surprised by a number of cases that presentment relapses $(n=14$ cases). Relapses in FA are not well explored in the literature, whereas information on compromised margins or incomplete excision is clearly defined for phyllodes tumors [25].

For FA, there only a few classic records and data in which they are described as entities that may recur. They may present as multiples in about 10 to $16 \%$ of cases, where patients may have two or four simultaneous nodules, which may present at the same time or at different times, discovered over the years [26]. Unlike, women with single FAs often have a family history of theses tumors [27]. An important observation in our work is that majority of our samples presented as relapses may actually be multiple FAs.

Analyzing the age of the patients regarding tumor recurrence, no difference was observed between the cases that presented tumor relapses and those that did not $(p=0.0662)$. A possible connection between the presence of multiple FAs and oral contraceptives has been proposed, but this connection is not yet well established in the literature [28]. Apparently cases with tumor relapses or multiple FAs did not focus on any specific age group.

The epidemiological data collected in the patient's medical records reveal that this series is comparable to others in the literature, reflecting the normal distribution of patients who present FAs as the main complaint without association with other comorbidities and the percentage of recurrence is also average level.

Still in an attempt to establish a possible correlation between the patients' clinical data and the presence of relapse, 
it was observed that the tumor size did not influence this correlation either. The size of FAs acquires importance in the reports in which they appear as giant FAs, which are difficult to excise, have worse post-operative esthetic results, but not necessarily relapse [29].

In the literature, there are few contributions to the evaluation of proliferation in FAs. In a line developed at UNIFESP, the influence of tamoxifen on cell proliferation in FAs was evaluated [24]. This study had a prospective randomized approach where they observed that proliferation rates were lower in epithelial cells when tamoxifen dose was $20 \mathrm{mg} /$ day (data measured by PCNA expression). In this study, proliferation was $32.4 \%$ in epithelial cells [30].

A few years later, a study evaluated 33 patients, and noted that proliferation data were not associated with oral contraceptives [31]. In another publication, with 75 patients evaluated, they found mean Ki67 results of 27.88 and 37.88 positive cells per thousand evaluated in the follicular and luteal phases, respectively. As in this study, proliferative activity in FAs did not differ between cases and did not suffer significant hormonal influence. The values were not associated with age, according to this study [32].

Although there are reports of FAs associated with areas of usual ductal hyperplasia, ductal hyperplasia with atypia and even carcinoma in situ, we did not observe areas of hyperplasia or epithelial cell proliferation in the H\&E sections evaluated to choose the study cases. In cases of FAs without anomalous proliferation, the Ki67 expression index in epithelial cells reflected the quiescent state of most of these lesions. It is interesting that proliferation was associated with a larger component of CKs expressing cells reflecting a basal profile to more proliferation and less differentiation.

\section{About cytokeratins}

Although CKs are traditionally used for differential diagnosis between epithelial lesions of various sites, or for identifying genetic diseases that affect the epidermis, they are also addressed in the literature involved with other clinical aspects.

In mastology, research with CKs has been used to detect circulating bone marrow tumor cells, and this feature correlates with survival [33]. Some CKs, in isolated and specific form, possibly participate in the invasion mechanism, as with CK18 and CK14 [34,35], or as prognostic indicators [36].

In adulthood, the mammary epithelium is composed of two morphologically distinguishable layers from luminal cells surrounding the lumen of the duct and myoepithelial cells accompanying the basement membrane. The distribution between basal, luminal and progenitor cells can be assessed by the relationship between the different CKs expressed in the same population. Based on the normal mammary epithelium, it is possible to verify that this relationship is variable. In addition to the transient changes related to the cyclic serum hormonal effect, there are personal as well as lifelong variations of the same woman. Thus, in one lobe, different phases of heterogeneous concomitant cell organization and differentiation can be observed at different stages of sequential development.

CK5 is considered a baseline profile marker, and is usually expressed in myoepithelial and basal cells [37]. When this CK is expressed together with $\mathrm{CK} 14$ it may reflect the presence of mammary progenitor cells capable of giving rise to both glandular and myoepithelial cells.

This CK5 is usually expressed in the mammary ductal epithelium. According to the literature, this expression reflects the contingent of non-luminal cells or outside the context of the fraction of cells that have already differentiated and will not divide but are generally in a more apical position [37]. Conversely, CK18 reflects the proportion of cells in differentiation status that usually express hormone receptors. The relationship between these two markers should not be concomitant, but rather inverse when observed in each cell type.

In fact, it was observed in the study that there was no correlation between these two markers regarding the expression of $\mathrm{CK} 5$ in basal cells and CK18 in luminal cells $(p=0.3438)$. Comparison with normal tissue, however, is not so elementary. There are few records in the literature, and those found have results that reflect the transience and heterogeneity of the subject. In samples from patients undergoing reduction mammoplasty, the percentage of mature lumen (ML), mature basal (MB), progenitor lumen (PL) and basal progenitor (BG) cells was extremely variable. The percentage of cells expressing $\mathrm{CK}_{14}$ and $\mathrm{CK} 18$, respectively, was also variable between cases. These values may suggest that the population undergoes variations in the proportion of cells at different stages of maturation physiologically. There is, however, a general average considering a study with 15 evaluated cases that is 30.07 of LM; from 11.51MB; from PL 20.27; and 10.34 BG [38]. These values were considered a reference in normal breast tissue for comparison with the data obtained in our study [38]. The presence of large amount of CK18 preserved expression in the majority of cases may reflect the preservation of differentiation process within FAs, regardless are possible influence stromal cells might exert.

When comparing the topography of CK5 positive cells, characteristic of basal ductal cells, our work showed controversial results. In contrast to normal tissue, where the predominance of positive cells is found throughout the ductal basal layer, in FAs the ductal cells were quite variable, and in some cases only 1 to $2 \%$ of the cells were CK5 positive in others a large part of the cells were positive, reaching up to $70 \%$ of the cells available in the sample. The distribution was also variable regarding the position of $\mathrm{CK}_{5}$-expressing cells, in some cases only basal cells were positive $(n=39)$, in other cases only apical cells were positive $(n=25)$, and in other cases presented positivity in both basal and luminal cells $(n=38)$.

Interestingly, the position of the cells did not obey a morphological segment consistent with cell differentiation. 
In this case we would have positive basal cells adjacent to positive luminals cells, however, in our work a more chaotic distribution of this reactivity was observed. In cases with cellular atrophy and progressive stromal hyalinization of FAs, CK5 positivity decreased considerably. One of the most likely explanations for this finding is that the three-dimensional spatial distribution of the ducts and their cells, as well as the ordered segmental differentiation of the ductal tree is partially compromised in the FAs. This impairment may be the result of the basic spatial alteration by the progressive strangulation of stromal expansion or, eventually, by the paracrine action of stromal cells next to the other ducts.

Overall, the percentage of CK5 positive cells was also higher in FAs than in normal breast tissue described in the literature. This difference may have a greater significance when we look at it in light of the results of a study with a broad line of research in breast cancer, where we have shown that $\mathrm{CK}_{5}$ positive cells are more present in heterogeneous tumors and constitute a portion of tumor cells that are often resistant to hormonal and radiotherapeutic treatment [39].

Basal cell profile and proliferation by Ki67 expression was also a different finding from normal breast tissue. The larger the number of basal cells, the higher the proliferation rate found. This relationship indicates that cell proliferation is related to an increase in the contingent of $\mathrm{CK}_{5}$ expressing cells, which may mean that the resulting cells are of this profile, or that proliferation is occurring to rearrange an imbalance of this cell differentiation profile.

The results of $\mathrm{CK}_{7}$ and $\mathrm{CK} 20$ expression in the $\mathrm{FA}$ epithelium studied in TMA achieved the expected, that is, strong, homogeneous and continuous positivity in the $\mathrm{CK} 7$ epithelium, and diffuse negativity for CK20, which is used for differential diagnosis in lesions of undetermined origin, where the suspicion of mammary origin requires the binomial $\mathrm{CK}_{7}^{+} /$ $\mathrm{CK}^{2} \mathrm{O}^{-}$to maintain this hypothesis. Gastrointestinal origin is indicated by the opposite binomial, ie, $\mathrm{CK}_{7}^{-} / \mathrm{CK}_{2} \mathrm{O}^{+}$.

The maintenance of this profile in FAs suggests that the alterations caused by the epithelial population being contained within an FA are not enough to alter the expression of these CKs and compromise their basic mammary cell profile. The absence of CK7 expression in stromal cells could suggest that none of the stromal cells sampled underwent epithelium-mesenchyma transformation (EMT), ie, they are not epithelioid cells with mesenchymal morphological characteristics.

CK14 is considered a basal cell marker, as is CK5. It is frequently studied in most studies that try to categorize breast cells according to different stages of differentiation. In contrast to $\mathrm{CK}_{5}$, it has been the subject of study in experimental mammary carcinogenesis where transient recovery of $\mathrm{CK}_{14}$ expression has been recorded, specifically in the invasive front of tumors. Recent translational research points out that early and subtle mechanisms such as the phosphorylation of CK segments may influence its stability and therefore impair and achieve cell adhesion $[40,41]$. Mutations in the CK14 gene ie cause Dowling - Meara EBS disease, by forming irregular cytoplasmic non-functioning aggregates [42].
The results of the comparison between $\mathrm{CK} 5$ and $\mathrm{CK} 14$ expression, as expected, show concomitance in the basal cells. This contingent of cells reflects the population of so-called progenitor cells in the breast, which could give rise to both glandular and myoepithelial cells. There are some isolated cases containing $\mathrm{CK} 5$ or $\mathrm{CK} 14$ expression in luminal position cells in our study, which may reflect a stage of atrophy. Patients older than 50 years old were shown a higher percentage of CK14-expressing ductal cells. With age, morphologically, myoepithelial cells decline and luminals acquire a profile more similar to basal ones [43]. As well, it was observed that the immunoexpression of $\mathrm{CK} 14$ and $\mathrm{CK} 18$ were not always restricted in the basal and luminal layers, respectively. These authors report that this controversial inversion of basal CK expression in luminal cells and / or luminal CK expression in basal cells may be present in type I lobes, ie, less differentiated from breast tissue. We may suggest that this pattern is correlated with lower mammary tissue differentiation in cases of FAs with this characteristic $[38,39]$.

Characterization of type I, II and III mammary lobes is not possible within fibroepithelial lesions. Another important factor of this observation is that it goes against the findings of Becker, et al. (2003), as they report that progenitor cells are usually in the luminal apical position in the middle of the luminal cells. The great majority of the cases of FAs studied presented a large percentage of CK18 positive cells, already expected in adult breast tissue. This high percentage demonstrates that ductal cells present in an FA maintain their differentiation capacity intact. The incidence of recurrence was not affected by the presence or absence of expression of this CK. The differentiation profile of a given tumor does not influence the appearance of other lesions [1].

The positive expression of CK18 was inversely proportional to the positive expression of $\mathrm{CK}_{5}$, being $\mathrm{CK}_{18} 8$ in luminal position and $\mathrm{CK}_{5}$ in basal position. This overview shows that this epithelium remains in a state of continuous maturation if conditions permit cell viability, and that the proportion of cells expressing basal and luminal CKs remains balanced in FAs. The study of CK18 expression in FAs is punctual in the literature. A pioneering study observed in frozen sections, by immunohistochemistry, the presence of CK18 $89.5 \%$ of the evaluated FAs. To study the mean differences in CK14 and CK18 expression in the tumor epithelium, the McNemmar test was used, which showed that there is disagreement in the proportion of expression of these CKs in the tumor epithelium $(p=0.0022)$. This result indicates that the expression of these two CKs is mutually exclusive. As CK18 is considered a marker of cell differentiation in ductal cells, it is suggested that it is present in luminal cells. This inverse relationship with CK14 identification of non-luminous cells reflects the specificity of these markers, and the degree of differentiation present in ductal cells in FAs. These acquire the luminal profile in a manner equivalent to that of normal breast tissue and acquire CK18 expression over CK14.

\section{Conclusions}

With the evaluation of the epithelial proliferation index 
performed, the FAs express CKs 5,7,14 and 18, and do not express CK 20 in distribution pattern and cell percentage comparable to non-tumoral breast tissue;

FAs have a contingent of progenitor cells when considered CK5 and CK14 positive, comparable or larger than non-tumoral breast tissue;

Ki67 is a nuclear antigen expressed in cells proliferation process. It is used as prognostic indicator, and is considered a luminal B feature when the level of immunoexpression exceeds $14 \%$ [16]. Its elevated expression was related to increased mitotic activity, cellular indifferentiation and invasion tendency. Only 1 case did not show positive expression to Ki67. Cell proliferation in FAs is comparable to normal breast tissue and correlates with $\mathrm{CK} 5$ expression.

\section{References}

1. Werner B, Horst B (2003) Evidence of progenitor cells of glandular and myoepithelial cell lineages in the human adult female breast epithelium a new progenitor (adult stem) cell concept. Cell Prolif 36: 73-84. Link: https://bit.ly/2U1Hhr5

2. Altmannsberger $M$, Dirk $T$, Droese $M$, Weber $K$, Osborn M (1986) Keratin polypeptide distribution in benign and malignant breast tumors: subdivision of ductal carcinomas using monoclonal antibodies. Virchows Arch B Cell Pathol Incl Mol Pathol 51: 265-275. Link: https://bit.ly/2UhCKjk

3. Celis JE, Gromova I, Cabezón T, Gromov P, Shen T, et al. (2007) Identification of a subset of breast carcinomas characterized by expression of cytokeratin 15: relationship between $\mathrm{CK} 15+$ progenitor/amplified cells and premalignant lesions and invasive disease. Mol Oncol 1: 321-349. Link: https://bit.ly/393Z5Ga

4. Reisenbichler ES, Balmer NN, Adams AL, Pfeifer JD, Hameed O (2011) Luminal cytokeratin expression profiles of breast papillomas and papillary carcinomas and the utility of a cytokeratin 5/p63/cytokeratin 8/18 antibody cocktail in their distinction Modern Pathology 24: 185-193. Link: https://go.nature.com/2U2yeGz

5. De Almeida HL (2004) Citoqueratinas. An Bras Dermatol 79: 135-145. Link: https://bit.ly/3a1FUy5

6. Coulombe PA, Omary MB (2002) 'Hard' and 'soft' principles defining the structure, function and regulation of keratin intermediate filaments. Curr Opin Cell Biol 14: 110-122. Link: https://bit.ly/2vBQ6yy

7. Hesse M, Magin TM, Weber K (2001) Genes for intermediate filament proteins and the draft sequence of the human genome: novel keratin genes and surprisingly high number of pseudogenes related to keratin genes 8 and 18 . J Cell Sci 114: 2569-2575. Link: https://bit.ly/2IYKXDD

8. van Roozendaal KE, Klijn JG, van Ooijen B, Claassen C, Eggermont AM, et al (1996) Differential regulation of breast tumor cell proliferation by stroma fibroblasts of various breast tissue sources. Int J Cancer 65: 120-125. Link: https://bit.ly/2xLwE2U

9. Krings G, Bean GR, Chen YY (2017) Fibroepithelial lesions; The WHO spectrum. Semin Diagn Pathol 34: 438-452. Link: https://bit.ly/398jsIW

10. Tan BY, Tan PH (2018) A Diagnostic Approach to Fibroepithelial Breast Lesions. Surg Pathol Clin 11: 17-42. Link: https://bit.ly/2U0YAIF

11. Pike AM, Oberman HA (1985) Juvenile ( cellular ) adenofibromas. A clinicopathologic study. Am J Surg Pathol 9: 730-736. Link: https://bit.ly/3dbfmMN

12. Hodges KB, Abdul-Karim FW, Wang M, Lopez-Beltran A, Montironi R, et al. (2009) Evidence for transformation of fibroadenoma of the breast to malignant phyllodes tumor. Appl Immunohistochem Mol Morphol 17: 345 350. Link: https://bit.ly/2x6CY4L

13. Abe M, Miyata S, Nishimura S, lijima K, Makita M, et al. (2011) Malignant transformation of breast fibroadenoma to malignant phyllodes tumor: Longterm outcome of 36 malignant phyllodes tumors. Breast Cancer 18: 268-272. Link: https://bit.ly/3923j1d

14. Wang ZC, Buraimoh A, Iglehart JD, Richardson AL (2006) Genome-wide analysis for loss of heterozygosity in primary and recurrent phyllodes tumor and fibroadenoma of breast using single nucleotide polymorphism arrays. Breast Cancer Res Treat 97: 301-319. Link: https://bit.ly/2UkoXbv

15. Loke BN, Md Nasir ND, Thike AA, Lee JYH, Lee,CS, et al. (2018) Genetics and genomics of breast fibroadenomas. J Clin Pathol 71: 381-387. Link: https://bit.ly/2x6DrUz

16. Noguchi S, Motomura K, Inaji H, Imaoka S, Koyama H (1993) Clonal Analysis of Fibroadenoma and Phyllodes Tumor of the Breast. Cancer Res 53: 4071-4074. Link: https://bit.ly/2vBZlie

17. Lim WK, Ong CK, Tan J, Thike AA, Ng CC, et al. (2014) Exome sequencing identifies highly recurrent MED12 somatic mutations in breast fibroadenoma. Nat Genet 46: 877-880. Link: https://bit.ly/2vwKNAg

18. Pareja F, Geyer FC, Kumar R, Selenica P, Piscuoglio S, et al. (2017) Phyllodes tumors with and without fibroadenoma-like areas display distinct genomic features and may evolve through distinct pathways. NPJ Breast Cancer 3: 40 . Link: https://bit.ly/3ba4nSc

19. Camp RL, Charette LA, Rimm DL (2000) Validation of tissue microarray technology in breast carcinoma. Lab Investig 80: 1943-1949. Link: https://bit.ly/2IUKouy

20. De Brot M, Rocha RM, Soares FA, Gobbi H (2012) Prognostic impact of the cancer stem cell related markers ALDH1 and EZH2 in triple negative and basal-like breast cancers. Pathology 44: 303-312. Link: https://bit.ly/2UnaPhK

21. Delves PJ, Martin SJ, Burton DR, Roitt IM (2013) Roitt's Essential Immunology. $13^{\text {th }}$ edn. Link: https://bit.ly/2WoVEqX

22. Cheang MCU, Chia SK, Voduc D, Gao D, Leung S, et al. (2009) Ki67 index, HER2 status, and prognosis of patients with luminal B breast cancer. J Natl Cancer Inst 101: 736-750. Link: https://bit.ly/2QsAnZD

23. Perou CM, Sørlie T, Eisen MB, van de Rijn M, Jeffrey SS, et al. (2000) Molecular portraits of human breast tumours. Nature 406: 747-752. Link: https://bit.ly/2xLSi77

24. Birnbaum D, Bertucci F, Ginestier C, Tagett R, Jacquemier J, et al. (2004) Basa and luminal breast cancers: basic or luminous? (review). Int J Oncol 25: 249258. Link: https://bit.ly/33wuzDG

25. Cowan ML, Argani P, Cimino-Mathews A (2016) Benign and low-grade fibroepithelial neoplasms of the breast have low recurrence rate after positive surgical margins. Mod Pathol 29: 259-265. Link: https://bit.ly/2J2bD6k

26. Foster ME, Garrahan N, Williams S (1988) Fibroadenoma of the breast: A clinical and pathological study. J R Coll Surg Edinb 33: 16-19. Link: https://bit.ly/3a33hqZ

27. Williamson MER, Lyons K, Hughes LE (1993) Multiple fibroadenomas of the breast: A problem of uncertain incidence and management. Ann R Coll Surg Engl 75: 161-163. Link: https://bit.ly/3dbirMR

28. Gregg WI (1966) Galactorrhea after Contraceptive Hormones. N Engl J Med 274: 1432. Link: https://bit.ly/33BN6ig

29. Sosin M, Feldman E (2012) Giant juvenile fibroadenoma: A case and review of novel modalities in treatment. Breast Dis 34: 35-38. Link: https://bit.ly/2xc5l1

30. Bernardes JR, Seixas MT, Lima GR, Marinho LC, Gebrim LH (2003) The effect of tamoxifen on PCNA expression in fibroadenomas. Breast $\mathrm{J}$ 9: 302-306. Link: https://bit.ly/2xanH2M 
31. Estevão RA, Baracat EC, Logullo ÂF, Oshima CT, Nazário AC (2007) Efficacy of estriol in inhibiting epithelial proliferation in mammary fibroadenoma: Randomized clinical trial. Sao Paulo Med J 125: 343-350. Link: https://bit.ly/2IZf3qQ

32. Rego MF, Navarrete MALH, Facina G, Falzoni R, Silva R, et al. (2009) Analysis of human mammary fibroadenoma by $\mathrm{Ki}-67$ index in the follicula and luteal phases of menstrual cycle. Cell Prolif 42: 241-247. Link: https://bit.ly/2UwMpmj

33. Effenberger KE, Borgen E, Eulenburg CZ, Bartkowiak K, Grosser A, et al. (2011) Detection and clinical relevance of early disseminated breast cancer cells depend on their cytokeratin expression pattern. Breast Cancer Res Treat 125 729-738. Link: https://bit.ly/2Wr4LY8

34. Woelfle U, Sauter G, Santjer S, Brakenhoff R, Pantel K (2004) Down-Regulated Expression of Cytokeratin 18 Promotes Progression of Human Breast Cancer Clin Cancer Res 10: 2670-2674. Link: https://bit.ly/3df9fH

35. Cheung KJ, Gabrielson E, Werb Z, Ewald AJ (2013) Collective invasion in breast cancer requires a conserved basal epithelial program. Cell 155: 16391651. Link: https://bit.ly/2xbmfNz

36. Van de Rijn $M$, Perou CM, Tibshirani $R$, Haas $P$, Kallioniemi $O$, et al (2002) Expression of cytokeratins 17 and 5 identifies a group of breast carcinomas with poor clinical outcome. Am J Pathol 161: 1991-1996. Link: https://bit.ly/3b7CoCv

37. Boecker W, Moll R, Dervan P, Burger H, Poremba C, et al. (2002) Usual ductal hyperplasia of the breast is a committed stem (progenitor) cell lesion distinct from atypical ductal hyperplasia and ductal carcinoma in situ. J Pathol 198 458-467. Link: https://bit.ly/2Ufj6nY

38. Arendt LM, Keller PJ, Skibinski A, Goncalves K, Naber SP, et al. (2014) Anatomical localization of progenitor cells in human breast tissue reveals enrichment of uncommitted cells within immature lobules. Breast Cancer Res 16: 1-16. Link: https://bit.ly/2xS4yTN

39. Kabos P, Haughian JM, Wang X, Dye WW, Finlayson C, et al. (2011) Cytokeratin 5 positive cells represent a steroid receptor negative and therapy resistant subpopulation in luminal breast cancers. Breast Cancer Res Treat 128: 45-55. Link: https://bit.ly/2Qtn1N3

40. Ku NO, Toivola DM, Strnad P, Omary MB (2010) Cytoskeletal keratin glycosylation protects epithelial tissue from injury. Nat Cell Biol 12: 876-885. Link: https://bit.ly/2QsF1Hc

41. Srikanth B, Vaidya MM, Kalraiya RD (2010) O-GlcNAcylation determines the solubility, filament organization, and stability of keratins 8 and 18. J Biol Chem 285: 34062-34071. Link: https://bit.ly/2UkwuH

42. Ishida-Yamamoto A, McGrath JA, Chapman SJ, Leigh IM, Birgitte Lane E, et al. (1991) Epidermolysis bullosa simplex (Dowling-meara type) is a genetic disease characterized by an abnormal keratin-filament network involving keratins K5 and K14. J Invest Dermatol 97: 959-968. Link: https://bit.ly/2wk5f7Y

43. Garbe JC, Pepin F, Pelissier FA, Sputova K, Fridriksdottir AJ, et al. (2012) Accumulation of multipotent progenitors with a basal differentiation bias during aging of human mammary epithelia. Cancer Res 72: 3687-3701. Link: https://bit.ly/39Ygb9T
Discover a bigger Impact and Visibility of your article publication with Peertechz Publications

\section{Highlights}

* Signatory publisher of ORCID

- Signatory Publisher of DORA (San Francisco Declaration on Research Assessment)

* Articles archived in worlds' renowned service providers such as Portico, CNKI, AGRIS, TDNet, Base (Bielefeld University Library), CrossRef, Scilit, J-Gate etc.

* Journals indexed in ICMJE, SHERPA/ROMEO, Google Scholar etc.

* OAI-PMH (Open Archives Initiative Protocol for Metadata Harvesting)

- Dedicated Editorial Board for every journa

* Accurate and rapid peer-review process

* Increased citations of published articles through promotions

* Reduced timeline for article publication

Submit your articles and experience a new surge in publication services (https://www.peertechz.com/submission).

Peertechz journals wishes everlasting success in your every endeavours.

Copyright: @ 2020 Bernardo M, et al. This is an open-access article distributed under the terms of the Creative Commons Attribution License, which permits unrestricted use, distribution, and reproduction in any medium, provided the original author and source are credited. 